\title{
Two- and Three-Component Visible Light Photoinitiating Systems for Radical Polymerization Based on Onium Salts: An Overview of Mechanistic and Laser Flash Photolysis Studies
}

\author{
María L. Gómez, Carlos M. Previtali, and Hernán A. Montejano \\ Departamento de Química, Universidad Nacional de Río Cuarto, Campus Universitario, 5800 Río Cuarto, Argentina \\ Correspondence should be addressed to Hernán A. Montejano,hmontejano@exa.unrc.edu.ar
}

Received 20 February 2012; Revised 7 May 2012; Accepted 22 June 2012

Academic Editor: Xavier Allonas

Copyright ( 2012 María L. Gómez et al. This is an open access article distributed under the Creative Commons Attribution License, which permits unrestricted use, distribution, and reproduction in any medium, provided the original work is properly cited.

A review of our work on two- and-three component photoinitiator systems is presented. The emphasis is in on visible light polymerization in aqueous media. The systems discussed comprise a synthetic dye as sensitizer and an onium salt as coinitiator, or a dye-amine-onium salt with the amine as coinitiator and the onium salt as an enhancer of the polymerization efficiency. The effect of the composition of the system on the photopolymerization kinetics was analyzed. To this end, the photophysics and photochemistry of the dye under polymerization conditions was explored by means of stationary and time-resolved spectroscopic methods. Different dyes and onium salts were investigated. The action mechanism of the different photoinitiators systems is discussed.

\section{Introduction}

The development of new materials by means of photopolymerization requires investigations aimed at discovering more efficient photoinitiator systems. Most of traditional photoinitiating systems employed UV radiation to generate active species. The use of sensitizers for visible light and the development of photopolymerizable system in aqueous media, make them environmental friendly and useful for applications in green chemistry or in the development of material for biological uses. Therefore, the development of photoinitiators based on a synthetic dye and a coinitiator was the subject of a large amount of work. Among the different coinitiators explored, a particular class corresponds to onium salts.

The development of applications involving onium salts (OS) in photoinitiation of polymerization [1] has been a topic of interest since the late 60s. Studies have been reported on ammonium salts [2], phosphonium [3], sulfonium [4], and iodonium salts [5] with aryl and/or alkyl groups on its structure. For similar applications, arsonium [6], pyridinium [7] and aryl tropylium [8] salts, have also been proposed in photoinitiation systems; these salts are capable of undergoing photochemical decomposition, producing active species suitable to initiate polymerization.

When these salts may act as electron acceptors, photosensitization was proposed to take place by reduction and posterior fragmentation of the cation $[9,10]$. Onium salts could act as a source of free radicals, radical cations, or Brönsted acids when exposed to light [11] and may be employed as efficient photoinitiators of radical, cationic, or mixed polymerization, [12-14]. The most widely used OS are diaryliodonium salts with chloride or perchlorate counterion. They have been employed extensively for cationic [15$18]$ and vinyl $[19,20]$ polymerization. The main practical limitation of the use of these salts is related to its low molar absorption coefficient above $300 \mathrm{~nm}$. To overcome this drawback, several photosensitizers are used to extend the spectral range suitable for electronic excitation. Aromatic ketones and polycyclic aromatic hydrocarbons (PAHs) are mainly used as photosensitizers for UV C radiation (300$400 \mathrm{~nm})$ [21-23].

Numerous papers have dealt with the mechanism of active species generation when PAHs are employed as 
TABLE 1: Names, formulae, and abbreviations of sensitizers, electron donor, and onium salts.



sensitizers in binary photoinitiating systems [24, 25]. Electron transfer and/or energy transfer from the excited PAH to the iodonium cation were suggested as the first reaction step in the initiation mechanism. In some cases, it is not clear whether the singlet or triplet excited state of the sensitizer is responsible for the interaction with the onium salt [24, $26,27]$. In a previous paper [28], we have investigated the interaction of diphenyliodonium cation $\left(\mathrm{DPI}^{+}\right)$with the excited singlet and triplet states of eight polycyclic aromatic hydrocarbons in acetonitrile solution. These results confirmed the electron transfer nature of the quenching process:

$$
{ }^{*} \mathrm{PAH}+\mathrm{DPI}^{+} \longrightarrow \mathrm{PAH}^{+}+\mathrm{DPI}^{\bullet}
$$

Singlet and triplet quenching rate constants were measured and they correlate well with the reaction driving force as expected for an electron transfer process. Moreover, the experimental data could be fitted to a Rehm-Weller mechanism with normal parameters. This result is a further confirmation of the electron transfer that occurs in the deactivation of electronically excited states of the PAHs by $\mathrm{DPI}^{+}$. The electron transfer reaction is followed by a very fast breakdown of DPI ${ }^{\bullet}$ radical $[29,30]$ to form the phenyl radical $\left(\mathrm{Ph}^{\bullet}\right)$, which is a reactive radical suitable for the initiation of vinyl polymerization.

In the present paper, we will focus on the research carried out by our group on two- and three-component photoinitiating systems for free radical polymerization containing onium salts. We will describe two-component photoinitiating systems employing sensitizers (SENs) adequate for visible light [31] and an onium salt, and three-component systems based on a sensitizer, an electron donor (ED), and an onium salt [32-34]. 
The schematic formulae of all the compounds involved in the photoinitiating systems studies are presented in Table 1. The experimental details are given elsewhere [31-34].

\section{Two-Component Systems: Diphenyl Iodonium Chloride (DPI) as a Coinitiator}

The most common photoinitiator systems in the visible region $(400-780 \mathrm{~nm})$ for radical polymerization involve a dye and an amine as an electron donor [35-38]. Active radicals are formed in a bimolecular electron transfer quenching of the triplet state of the dye by the amine. We have previously reported on the photoreduction of several dyes (flavins, safranine, resazurin, and resorufin) by amines and the use of these systems as suitable photoinitiators of vinyl polymerization using visible irradiation [36, 39-42].

Two-component systems based on an onium salts in conjunction with synthetic dyes are also an alternative for photoinitiation $[7,31,43]$. These systems have been widely employed in light-cured epoxy dental polymer systems; in this case cationic photopolymerization takes place $[7,25,44-$ 47]. On the other hand, mechanistic studies dealing with dyes/OS as photoinitiator systems for radical polymerization are scarce $[18,48]$.

In previous study, we found that dyes of the family of phenoxazines, resazurin (RZ) and resorufin (RF), in the presence of triethanolamine (TEOA) are efficient photoinitiators of aqueous acrylamide (AA) polymerization [38]. Later on we decided to explore the possibility of using RZ/OS as a photoinitiation system. The photophysics and photochemistry of RZ and RF in the presence of an electron acceptor was investigated, and it was found that the dyes in their excited state might also act as electron donors [49]. In a subsequent paper, the excited states quenching of RZ by DPI in water solution at $\mathrm{pH} 10$ was presented. In this work we showed the ability of this two-component system for the efficient polymerization of AA in aqueous solution [31]. The polymerization on visible irradiation in the presence of resazurin without a coinitiator was negligible; however, it proceeds efficiently in the presence of DPI. It was found that the RZ/DPI combination undergoes photoreaction via intermolecular electron transfer, resulting in photobleaching of the dye and generation of active radical species by subsequent decomposition of $\mathrm{DPI}^{\bullet}$ radical.

The comparison of the systems RZ/DPI and RZ/TEOA is presented in Figure 1. The kinetics of AA polymerization using monochromatic light of $602 \mathrm{~nm}$ was followed by dilatometry. For both initiator systems, the polymerization follows a typical radical chain mechanism with second-order termination, yielding in both cases high-molecular-weight polymers [31]. Even though the efficiency as coinitiator is lower for DPI than that of TEOA, their magnitudes are comparable. This shows that the system RZ/DPI may be considered as an attractive alternative for two-component visible light photoinitiator system.

The quenching of the singlet and triplet excited states of RZ by DPI was investigated by time-resolved fluorescence spectroscopy and by laser flash photolysis. Due to the

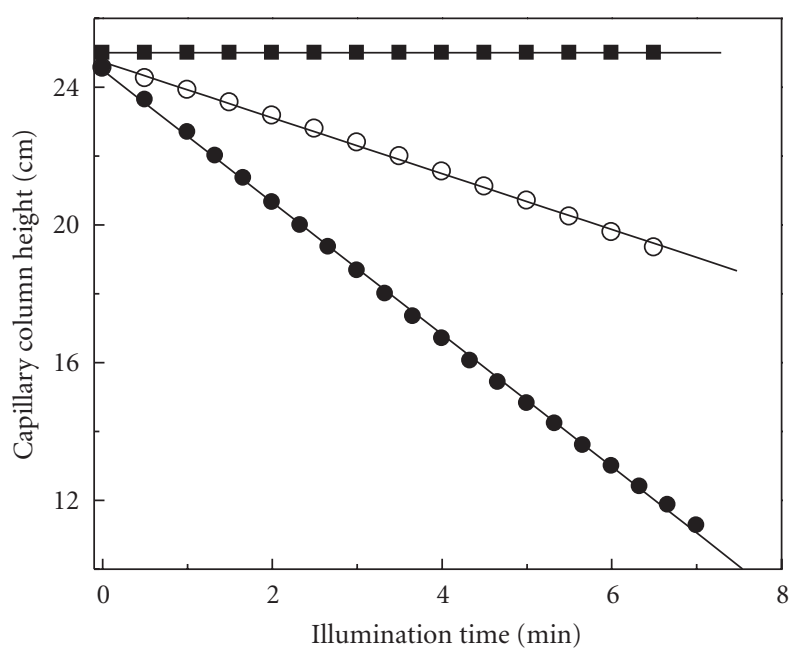

FIGURE 1: Determination of initial rates of polymerization of Rz $4 \times$ $10^{-6} \mathrm{M}$ for the photopolymerization of AA $2 \mathrm{M}$ in water at $\mathrm{pH}=10$ : in absence of coinitiator ( $\mathbf{\square})$, in the presence of TEOA: $5 \times 10^{-3} \mathrm{M}$ $(\bullet)$, and in the presence of DPI: $5 \times 10^{-3} \mathrm{M}(\circ)$.

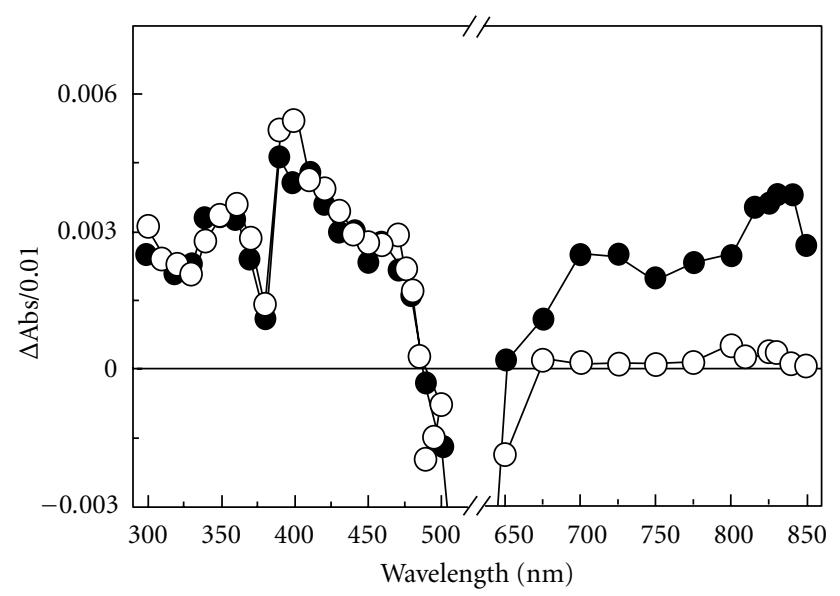

Figure 2: Transient absorption spectra of $\mathrm{Rz} 1 \times 10^{-5} \mathrm{M}$ in the absence $(\bullet)$ and presence $(\circ)$ of $0.02 \mathrm{M} \mathrm{DPI}$ in water at $\mathrm{pH} 10(1 \mu \mathrm{s}$ after laser flash).

short lifetime of the excited singlet $(0.7 \mathrm{~ns})$, fluorescence quenching was not observed at the concentrations employed in the polymerization experiments. On the other hand, the triplet sate was quenched with a rate constant of $3 \times$ $10^{6} \mathrm{M}^{-1} \mathrm{~s}^{-1}$. The transient absorption spectrum of RZ in the presence of DPI can be seen in Figure 2.

In the absence of DPI at $1 \mu \mathrm{s}$ after the laser pulse, two bands can be seen, one in the $700-850 \mathrm{~nm}$ region assigned to the triplet and the other at $300-480 \mathrm{~nm}$ assigned to the combined absorption of the triplet and the radical ions formed by an autoquenching process via electron transfer [42]. The negative absorption $(500-620 \mathrm{~nm})$ and the valley at $379 \mathrm{~nm}$ indicate the depletion of the ground state. The triplet lifetime in water at $\mathrm{pH} 10$ was ca. $90 \mu \mathrm{s}$. An increase in the absorption near $460 \mathrm{~nm}$ can be seen in the presence of DPI, while the T-T absorption has completely decayed. The band 


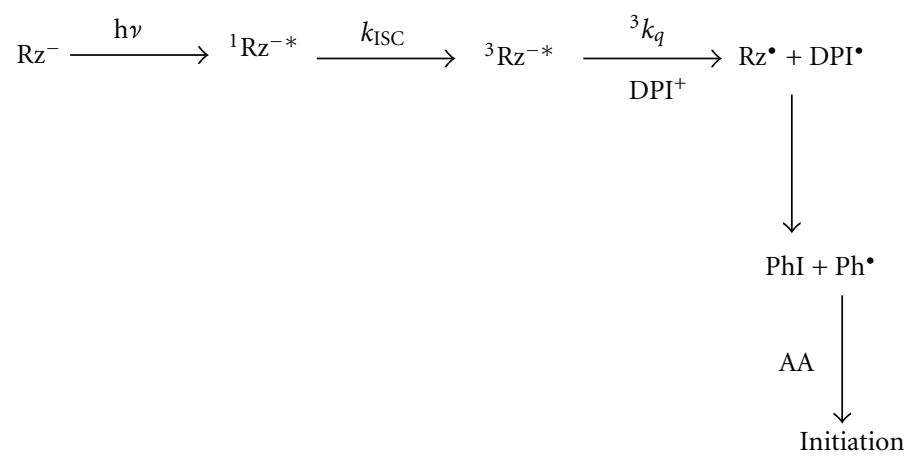

SCHEME 1

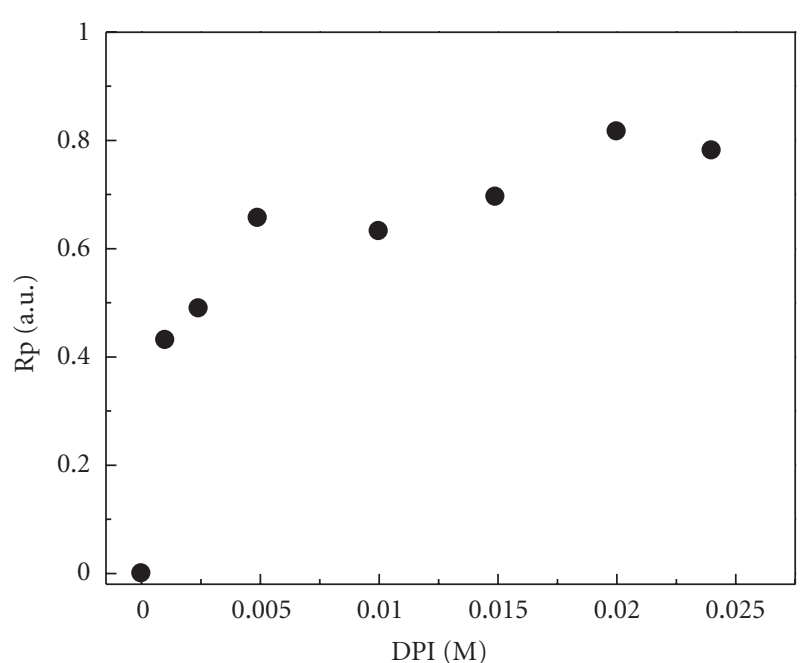

FIGURE 3: initial rates of polymerization of AA $2 \mathrm{M}$ in water $(\mathrm{pH}=10)$ in the presence of $\mathrm{Rz} 4 \times 10^{-6} \mathrm{M}$ as a function of DPI concentration.

at $460 \mathrm{~nm}$ can be assigned to the semioxidized radical form of the dye [42]. These observations can be attributed to an electron transfer reaction from the triplet excited state of the dye to the onium salt. The phenyl radical produced by fragmentation of the DPI is not readily detectable in the spectral region near UV and visible [50]; nevertheless, it is assumed to be formed with the same yield than the semioxidized form of the dye (Scheme 1).

In order to check the consistency of the mechanism, the polymerization rate was measured at different DPI concentrations (Figure 3). These data show an increase in the polymerization rate by the addition of the onium salt up to $5 \mathrm{mM}$. Above this concentration, the rate increased slightly with the subsequent increase in the concentration of DPI.

The linear dependence of the polymerization rate with AA concentration and the square root dependence with light intensity was checked. Therefore, it may be assumed that the classical expression for a free radical addition polymerization is valid. In this case, the square of the polymerization rate

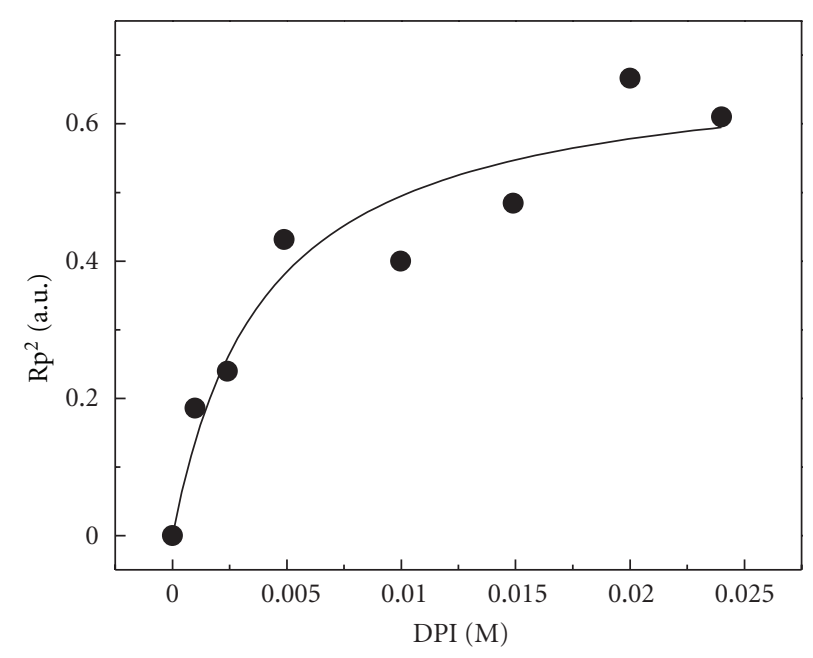

FIGURE 4: Plot of the square of the polymerization rate of AA $2 \mathrm{M}$ in water $(\mathrm{pH}=10)$ in the presence of $\mathrm{Rz} 4 \times 10^{-6} \mathrm{M}$ as a function of DPI concentration. The solid line corresponds to the active radicals quantum yield calculated with the kinetics parameters obtained by laser flash photolysis.

may be correlated with the theoretical quantum yield of initiating radicals, as given by (2) as follows:

$$
\mathrm{Rp} \propto[\mathrm{AA}] \Phi_{R}{ }^{1 / 2}
$$

Figure 4 shows a plot of the square of the relative polymerization rate as a function of DPI concentration. Since there is no quenching of the singlet excited state of the dye by DPI, it can be considered that the initiation of polymerization is promoted exclusively by phenyl radicals derived from the deactivation of the triplet state of the dye by the onium salt [31]. The solid line represents the theoretical radical yield calculated with the kinetics parameters as measured by laser flash photolysis [31]. The good concordance of the experimental data with the theoretical model can be taken as a confirmation of the mechanism. 


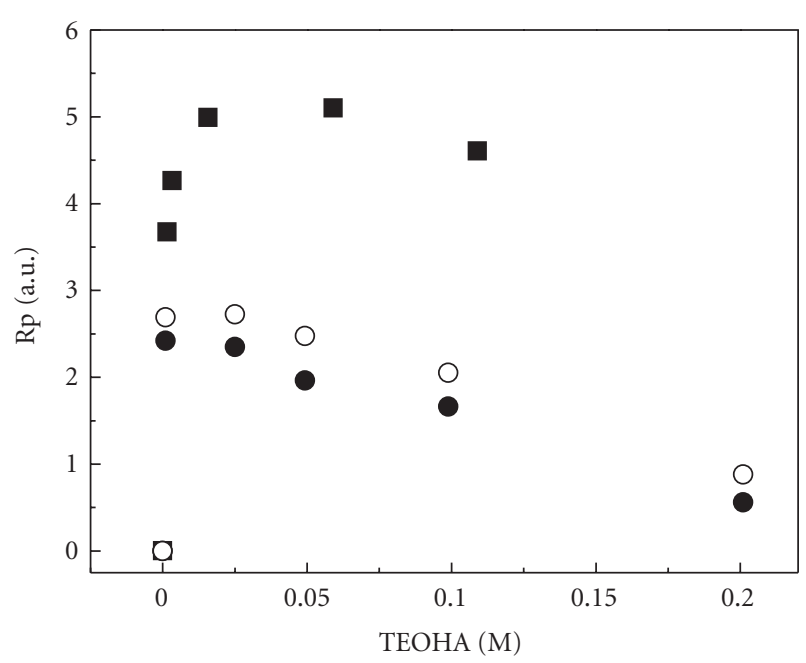

Figure 5: Polymerization rate $(\mathrm{Rp})$ as a function of TEOA concentration. In the absence of OS $(\bullet)$, in the presence of TPS ( $\circ)$ and in the presence of DPI $(\boldsymbol{\square})$. Saf: $1 \times 10^{-5} \mathrm{M}$ and OS: $0.01 \mathrm{M}$.

\section{Three-Component Photoinitiating Systems Involving Onium Salts}

Three-component photoinitiator systems were developed as an improvement of the known two-component photoinitiators systems $[13,19,20,32-34,51,52]$. The most common third component was an onium salt, and among them the majority of studies employed DPI. In general, it was observed that the presence of the third component enhances significantly the polymerization rate $[12,13,19]$. In our group, several photoinitiating systems based on dyes and amines have been studied in detail [36-39], and it was decided to investigate the effect of adding an onium salt to them.

In this section, we resume the results of the effect of the incorporation of onium salts (OS) as third component to the photoinitiating system based on the cationic dye Safranine O (Saf) and TEOA in aqueous media [32-34]. The onium salts employed were DPI, triphenylsulfonium triflate, (TPS) tetraphenylphosphonium chloride (TPP), and tetraphenylarsonium chloride (TPA). Their formulae are presented in Table 1.

The system Saf/TEOA initiates vinyl polymerization efficiently [36, 37] when irradiated at $520 \mathrm{~nm}$. It was found that the incorporation of DPI or TPS increases in a significant way the polymerization rate $[32,34]$. On the other hand, although TPP and TPAs have little effect on the photopolymerization, interesting effects over the photophysical properties of the system were found in the presence of these two salts [33].

Figure 5 displays the polymerization rate versus TEOA concentration for DPI and TPS. The effect of the OS is noticeable for all the TEOA concentration range.

From the dependence of the polymerization rate on monomer concentration and light intensity in the absence and presence of the different OS, it was confirmed that the rate law conforms to the classic vinyl polymerization mechanism with second-order termination.

In order to understand the action mechanism of the OS, a detailed photophysical and photochemical study on the photoinitiating mechanism in the presence of the OS was undertaken. Continuum irradiation and laser flash photolysis experiments were carried out.

A fast photobleaching of the dye was observed when Saf was irradiated in the presence of TEOA. However, in the presence of OS, the photobleaching was inhibited [32, 34]. DPI is the most efficient inhibitor of the photobleaching of the dye followed by TPS with a less important protective effect. TPP and TPAs have little effect on the photobleaching. The photobleaching mechanism most likely involves an electron transfer step from the amine to the excited triplet of the dye as the first step, followed by dark radical reactions. It was demonstrated that the quenching of the triplet state by the EDs involves an initial deprotonation step. In a second step, the deprotonated triplet reacts with a second molecule of the ED in an electron transfer reaction [36].

The inhibitory effect of the OS may be understood in terms of its effect of the secondary reactions, since the triplet quenching by TEOA is not affected by the presence of the OS.

According to (2), the square of the polymerization rate is proportional to the quantum yield of initiating radicals. Assuming that the active radicals are formed in equal yield than the semireduced form of the dye, the quantum yield of initiating radicals were estimated from the long-lived absorbance measured by laser flash photolysis at $425 \mathrm{~nm}$, assigned to the radical anion of the dye $\left(\mathrm{Saf}^{0^{-}}\right)$[53].

In Figure 6 the polymerization rate and the radical quantum yield are shown as a function of DPI concentration. It can be seen that the accelerating effect of DPI on the rate is much more important than the increase in the yield of radicals in the initiation process. These results show the effect of DPI in the polymerization rate cannot be attributed only to an augment in the yield of active radicals [34].

To obtain a deeper understanding of the action mechanism of the salt, the polymerization rate was related to other physicochemical properties of the system. A possible effect of DPI is the formation of microheterogeneous domains due to aggregation of the salt. In effect, a considerable increase in the light scattering of the solutions at high concentrations of DPI was detected, although the solutions remained clear. The effect of aggregation on the photopolymerization rate in aqueous media was observed by other authors employing different monomers and was attributed to the incorporation of the dye and coinitiator molecules to the aggregates, called a hydrotropic effect [54-56].

Therefore, we investigated the effect of aggregation of DPI by light scattering in water and related it to polymerization rate and the fluorescence and triplet quantum yields of Saf in these solutions. In Figure 7, the effect of DPI concentration on the photophysical parameters of the dye, light scattering intensity, and polymerization rate is shown. The photophysical parameters refer to the dye in the presence of DPI but in the absence of amine and monomer.

Two regions are distinguished in Figure 7 , a plateau in the $10^{-5}-10^{-3} \mathrm{M}$ (region $\mathrm{A}$ ) and beyond $10^{-3} \mathrm{M}$ (region $\mathrm{B}$ ), 


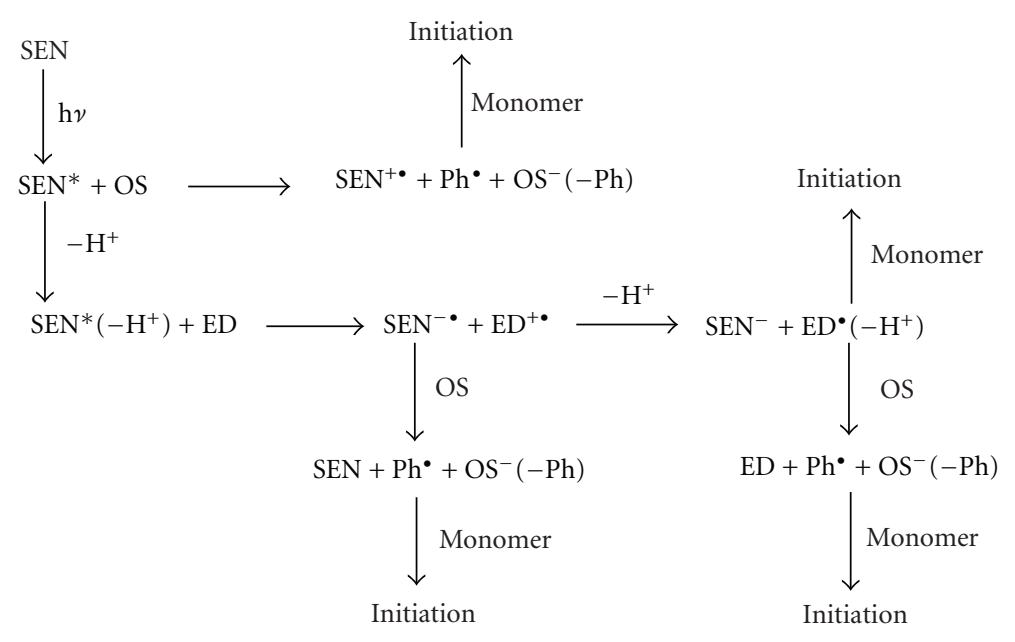

Scheme 2

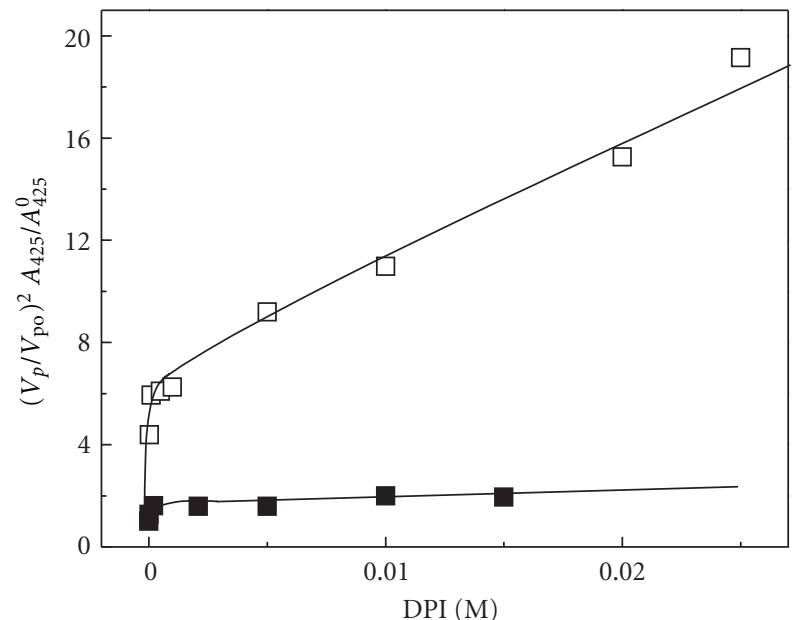

Figure 6: Plot of the square of the polymerization rate $(\boldsymbol{\square})$ and the radical yield $(\square)$ measured as the long-lived absorption at $425 \mathrm{~nm}$ by laser flash photolysis as a function of DPI concentration relative to the values in the absence of DPI. TEOA concentration is $0.027 \mathrm{M}$.

where the photophysical parameters, light scattering, and polymerization rate present an important increment. The abrupt change in light scattering in region $\mathrm{B}$ may be related to the aggregation of the salt. The nature of the aggregates could not be clearly established; however, the light scattering due to the aggregation of DPI was much higher than that observed for a common surfactant such as SDS in the same concentration range, within which normal micelles are formed. The concentration dependence of the light scattering closely resembles that of the photophysical properties and the polymerization rate. It can be concluded that this important effect in polymerization rate could be correlated with the onset of the aggregation phenomenon of the salt. Nevertheless, although the polymerization rate increased by a factor of about 4 at $0.01 \mathrm{M} \mathrm{DPI}$, the triplet yield was only 1.6 times higher. Consequently, the effect of DPI on the polymerization rate could not be ascribed only to an enhancement of the intersystem crossing.

Several explanations may be offered for the effect of the aggregation on the photopolymerization. First, the adsorption of the dye to the DPI aggregates may be considered, although this may be of minor importance because of the positive charge of both the dye and the aggregates. Moreover, the absorption and fluorescence of the dye remained practically unchanged, except for a minor increase (ca. 10\%) in the fluorescence yield as can be observed in Figure 7. A plausible explanation for the increase for the increase in the polymerization rate may be the interaction of the growing chains with the aggregates. This could reduce the termination rate and also affect the propagation rate by a local concentration effect if it is assumed that the monomer presents some preference for the particles.

In summary, the increase in polymerization rate for the three-component photoinitiating system compared with the two-component system may be attributed to several factors, among them: an increase in the yield of radicals, as observed from the semireduced form of the dye measure by laser flash [32] although of minor importance this could be contribute to augment the photoinitiation efficiency. Another, and more important, factor is the hydrotropic behavior $[33,34]$, with a minimum hydrotrope concentration ca. $1 \times 10^{-3} \mathrm{M}$, these aggregates could be acting as efficient solubilizers of monomer increasing the polymerization rate. Finally, the reduction of the onium cation must be considered; the possible participation of the onium cations in reactions with the excited states of the dye or with the existing radicals could be an alternative route of generation of active radicals [34]. In this regard, it is interesting to note that when the different OS are compared the increase in polymerization rate follows the trend of the reduction potentials [57-59].

The different pathways of photoinitiation proposed for these three-component systems are summarized in Scheme 2. 


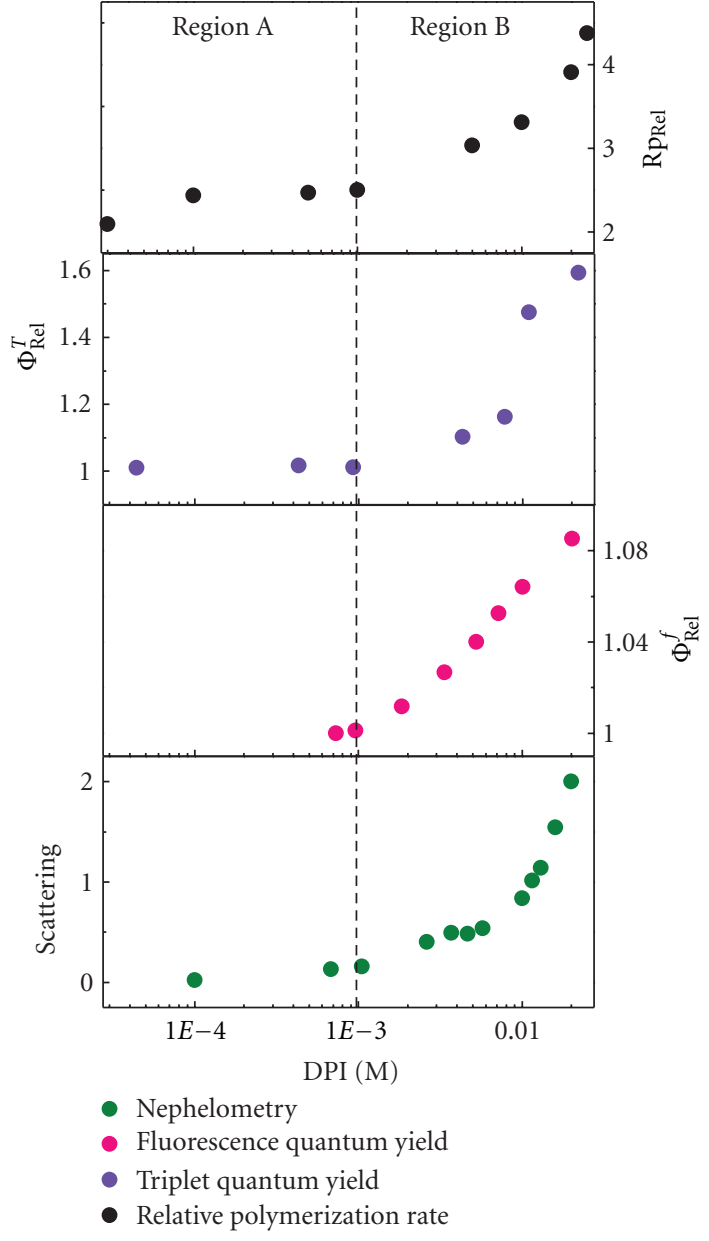

FIGURE 7: Effect of DPI concentration on the scattering as measured by nephelometry $(\bullet)$, fluoresence quantum yield $(\bullet)$, triplet quantum yield $(\bullet)$ and relative polymerization rate $(\bullet)$. All measurements in water are at $25^{\circ} \mathrm{C}$.

\section{Acknowledgments}

The authors are grateful to Consejo Nacional de Investigaciones Científicas y Técnicas (CONICET) of Argentina, Universidad Nacional de Río Cuarto, and Agencia Nacional de Promoción Científica y Tecnológica (FONCYT) for financial support. M. L. Gómez, C. M. Previtali, and H. A. Montejano are scientific members of CONICET.

\section{References}

[1] J. V. Crivello, UV Curing, Science and Technology, vol. 23, Technology Marketing, Norwalk, Conn, USA, 1978.

[2] T. D. Walsh and R. C. Long, "Photochemistry of aromatic ions. Photolysis of quaternary anilinium salts," Journal of the American Chemical Society, vol. 89, p. 3944, 1967.

[3] C. E. Griffin and M. L. Kauffman, "Photolysis of triarylphosphines," Tetrahedron Letters, vol. 6, pp. 769-772, 1965.

[4] S. L. Nickol and J. A. Kampmeier, "Photolysis of a charge transfer complex. Triphenylsulfonium iodide," Journal of the American Chemical Society, vol. 95, no. 6, pp. 1908-1915, 1973.
[5] H. Irving and R. W. Reid, "The photochemical decomposition of diphenyliodonium iodide," Journal of the Chemical Society, p. 2078, 1968.

[6] R. Vasishitha and A. K. Srivastava, "Mechanistic and kinetic studies of the polymerization of styrene photoinitiated by p-acetyl benzylidene triphenylarsonium ylide," Journal of Photochemistry and Photobiology A, vol. 47, p. 379, 1989.

[7] Q. Q. Zhu and W. Schnabel, "Cationic photopolymerization under visible laser light: polymerization of oxiranes with coumarin/onium salt initiator systems," Polymer, vol. 37, no. 18, pp. 4129-4133, 1996.

[8] J. V. Gražulevičius, R. Kavaliunas, R. Lazauskaite, V. M. Getautis, and M. Daškevičiene, "Photopolymerization of carbazolyloxiranes with sulphonium and tropylium salts," Journal of Photochemistry and Photobiology A, vol. 110, pp. 8589, 1997.

[9] H. J. Timpe, K. P. Kronfeld, U. Lammel, J. P. Fouassier, and D. J. Lougnot, "Time-resolved laser spectroscopy of the sensitized photolysis of iodonium salts," Journal of Photochemistry and Photobiology A, vol. 49, p. 317, 1989.

[10] A. Kunze, U. Müller, K. Titles, J.-P. Fouassier, and F. MorletSavary, "Triplet quenching by onium salts in polar and nonpolar solvents," Journal of Photochemistry and Photobiology A, vol. 110, no. 2, pp. 115-122, 1997.

[11] J. F. Rabek, Mechanisms of Photophysical Reactions of Polymers, Wiley, Chichester, UK, 1988.

[12] J. P. Fouassier, D. Ruhlmann, Y. Takimoto, M. Harada, and M. Kawabata, "New three-component initiation systems in UV curing: a time-resolved laser-spectroscopy investigation," Journal of Polymer Science, Part A, vol. 31, no. 9, pp. 22452248, 1993.

[13] A. Erddalane, J. P. Fouassier, F. Morlet-Savary, and Y. Takimoto, "Efficiency and excited state processes in a threecomponent system, based on thioxanthene derived dye/ amine/additive, usable in photopolymer plates," Journal of Polymer Science, Part A, vol. 34, no. 4, pp. 633-642, 1996.

[14] T. G. Yildirim, Y. Hepuzer, G. Hizal, and Y. Yağci, "Synthesis of block copolymers by transformation of photosensitized cationic polymerization to stable free radical polymerization," Polymer, vol. 40, no. 13, pp. 3885-3890, 1999.

[15] G. Manivannan, J. P. Fouassier, and J. V. Crivello, "Chlorothioxanthone-onium salts. Efficient photoinitiators of cationic polymerization," Journal of Polymer Science, Part A, vol. 30, no. 9, pp. 1999-2001, 1992.

[16] Y. Yağci and I. Reetz, "Externally stimulated initiator systems for cationic polymerization," Progress in Polymer Science, vol. 23, no. 8, pp. 1485-1538, 1998.

[17] Y. Yagci and Y. Hepuzer, "A novel visible light initiatiating system for cationic polymerization," Macromolecules, vol. 32, no. 19, pp. 6367-6370, 1999.

[18] Y. Toba, "The design of photoinitiator systems," Journal of Photopolymer Science and Technology, vol. 16, no. 1, pp. 115$118,2003$.

[19] K. S. Padon and A. B. Scranton, "Mechanistic investigation of a three-component radical photoinitiator system comprising methylene blue, N-methyldiethanolamine, and diphenyliodonium chloride," Journal of Polymer Science, Part A, vol. 38, no. 11, pp. 2057-2066, 2000.

[20] D. Kim and A. Scranton, "The role of diphenyl iodonium salt (DPI) in three-component photoinitiator systems containing methylene blue (MB) and an electron donor," Journal of Polymer Science, Part A, vol. 42, no. 23, pp. 5863-5871, 2004.

[21] E. W. Nelson, T. P. Carter, and A. B. Scranton, "Role of the triplet state in the photosensitization of cationic 
polymerizations by anthracene," Journal of Polymer Science, Part A, vol. 33, no. 2, pp. 247-256, 1995.

[22] J. V. Crivello and M. Sangermano, "Visible and longwavelength photoinitiated cationic polymerization," Journal of Polymer Science, Part A, vol. 39, pp. 343-356, 2001.

[23] H.-J. Timpe and A. G. Rajendran, "Light-induced polymer and polymerization reactions-42. A kinetic study of cationic photopolymerization with (benzoin derivative)/(onium salt) systems," European Polymer Journal, vol. 27, pp. 77-83, 1991.

[24] U. Müller and I. Zücker, "Sensitized proton formation using lipophilic substituted iodonium salts," Journal of Photochemistry and Photobiology A, vol. 120, p. 93, 1999.

[25] Y. Toba, M. Saito, and Y. Usui, "Cationic photopolymerization of epoxides by direct and sensitized photolysis of onium tetrakis(pentafluorophenyl)borate initiators," Macromolecules, vol. 32, no. 10, pp. 3209-3215, 1999.

[26] H.-J. Timpe, S. Ulrich, and J.-P. Fouassier, "Photochemistry and use of decahydroacridine-1,8-diones as photosensitizers for onium salt decomposition," Journal of Photochemistry and Photobiology A, vol. 73, pp. 139-150, 1993.

[27] R. J. DeVoe, P. M. Olofson, and M. R. V. Sahyun, "Photochemistry and photophysics of 'onium slats," in Advances in Photochemistry, D. Volmon, G. Hammond, and D. Neckers, Eds., vol. 17, pp. 313-335, John Wiley and Sons, 1992.

[28] M. L. Gómez, H. A. Montejano, and C. M. Previtali, "Excited states interaction of polycyclic aromatic hydrocarbons with diphenyliodonium chloride. The effective one electron reduction potential of diphenyliodonium cation," Journal of Photochemistry and Photobiology A, vol. 197, pp. 18-24, 2008.

[29] R. J. DeVoe, M. R. V. Sahyun, N. Serpone, and D. K. Sharma, "Transient intermediates in the photolysis of iodonium cations," Canadian Journal of Chemistry, vol. 65, p. 2342, 1987.

[30] J. L. Dektar and N. P. Hacker, "Photochemistry of diaryliodonium salts," Journal of Organic Chemistry, vol. 55, no. 2, pp. 639-647, 1990.

[31] M. L. Gómez, C. M. Previtali, H. A. Montejano, and S. G. Bertolotti, "Photoreaction and photopolymerization studies on phenoxazin dyes/diphenyliodonium chloride salt," Journal of Photochemistry and Photobiology A, vol. 188, pp. 83-89, 2007.

[32] M. L. Gómez, V. Avila, H. A. Montejano, and C. M. Previtali, "A mechanistic and laser flash photolysis investigation of acrylamide polymerization photoinitiated by the three component system safranine-T/triethanolamine/diphenyliodonium chloride," Polymer, vol. 44, no. 10, pp. 2875-2881, 2003.

[33] M. L. Gómez, H. A. Montejano, M. D. V. Bohorquez, and C. M. Previtali, "Photopolymerization of acrylamide Initiated by the three-component system Safranine/Triethanolamine/ Diphenyliodonium chloride: the effect of the aggregation of the salt," Journal of Polymer Science, Part A, vol. 42, no. 19, pp. 4916-4920, 2004.

[34] M. L. Gómez, C. M. Previtali, and H. A. Montejano, "Phenylonium salts as third component of the photoinitiator system safranine $\mathrm{O} /$ triethanolamine: a comparative study in aqueous media," Polymer, vol. 48, no. 8, pp. 2355-2361, 2007.

[35] M. V. Encinas and E. A. Lissi, Polymeric Materials Encyclopedia, vol. 7, Edited by J. C. Salomone, CRC, Boca Raton, Fla, USA, 1996.

[36] C. M. Previtali, S. G. Bertolotti, M. G. Neumann, I. A. Pastre, A. M. Rufs, and M. V. Encinas, "Laser flash photolysis study of the photoinitiator system safranine T-aliphatic amines for vinyl polymerization," Macromolecules, vol. 27, no. 25, pp. 7454-7458, 1994.
[37] M. V. Encinas, A. M. Rufs, M. G. Neumann, and C. M. Previtali, "Photoinitiated vinyl polymerization by safranine T/triethanolamine in aqueous solution," Polymer, vol. 37, no. 8, pp. 1395-1398, 1996.

[38] L. Villegas, M. V. Encinas, A. M. Rufs, C. Bueno, S. Bertolotti, and C. M. Previtali, "Aqueous photopolymerization with visible-light photoinitiators: acrylamide polymerization photoinitiated with a phenoxazine dye/amine system," Journal of Polymer Science, Part A, vol. 39, no. 23, pp. 4074-4082, 2001.

[39] M. V. Encinas, C. M. Previtali, S. G. Bertolotti, and M. Neumann, "The interaction of the excited states of safranine T with aliphatic amines in organic solvents," Photochemistry and Photobiology, vol. 62, p. 65, 1995.

[40] G. Porcal, S. G. Bertolotti, C. M. Previtali, and M. V. Encinas, "Electron transfer quenching of singlet and triplet excited states of flavins and lumichrome by aromatic and aliphatic electron donors," Physical Chemistry Chemical Physics, vol. 5, no. 19, pp. 4123-4128, 2003.

[41] M. G. Neumann, C. C. Schmitt, C. M. Previtali, and S. G. Bertolotti, "Photoreduction of resazurin in the presence of aliphatic amines," Dyes and Pigments, vol. 32, no. 2, pp. 9399, 1996.

[42] C. Bueno, M. L. Villegas, S. G. Bertolotti, C. M. Previtali, M. G. Neumann, and M. V. Encinas, "The excited-state interaction of resazurin and resorufin with amines in aqueous solutions. Photophysics and photochemical reaction," Photochemistry and Photobiology, vol. 76, pp. 385-390, 2002.

[43] J. P. Fouassier, X. Allonas, and D. Burget, "Photopolymerization reactions under visible lights: principle, mechanisms and examples of applications," Progress in Organic Coatings, vol. 47, no. 1, pp. 16-36, 2003.

[44] G. Manivannan and J. P. Fouassier, "Primary processes in the photosensitized polymerization of cationic monomers," Journal of Polymer Science, Part A, vol. 29, no. 8, pp. 11131124, 1991.

[45] J. V. Crivello and M. Jang, "Anthracene electron-transfer photosensitizers for onium salt induced cationic photopolymerizations," Journal of Photochemistry and Photobiology A, vol. 159, pp. 173-188, 2003.

[46] D. A. Tilbrook, R. L. Clarke, N. E. Howle, and M. Braden, "Photocurable epoxy-polyol matrices for use in dental composites I," Biomaterials, vol. 21, no. 17, pp. 1743-1753, 2000.

[47] F. Millich, L. Jeang, J. D. Eick, C. C. Chappelow, and C. S. Pinzino, "Elements of light-cured epoxy-based dental polymer systems," Journal of Dental Research, vol. 77, no. 4, pp. 603608, 1998.

[48] Y. He, W. Zhou, F. Wu, M. Li, and E. Wang, "Photoreaction and photopolymerization studies on squaraine dyes/iodonium salts combination," Journal of Photochemistry and Photobiology A, vol. 162, pp. 463-471, 2004.

[49] H. A. Montejano, M. Gervaldo, and S. G. Bertolotti, "The excited-states quenching of resazurin and resorufin by $\mathrm{p}$ benzoquinones in polar solvents," Dyes and Pigments, vol. 64, no. 2, pp. 117-124, 2005.

[50] D. Weldon, S. Holland, and J. C. Scaiano, "Temperature dependence of the reactions of phenyl radicals with 1,1diphenylethylene, carbon tetrachloride, and cyclohexene," Journal of Organic Chemistry, vol. 61, no. 24, pp. 8544-8546, 1996.

[51] Y. Bi and D. C. Neckers, "A visible light initiating system for free radical promoted cationic polymerization," Macromolecules, vol. 27, no. 14, pp. 3683-3693, 1994. 
[52] C. Grotzinger, D. Burget, P. Jacques, and J. P. Fouassier, "Visible light induced photopolymerization: speeding up the rate of polymerization by using co-initiators in dye/amine photoinitiating systems," Polymer, vol. 44, no. 13, pp. 3671$3677,2003$.

[53] C. E. Baumgartner, H. H. Richtol, and D. A. Aikens, "Transient photochemistry of safranine-O," Photochemistry and Photobiology, vol. 34, p. 17, 1981.

[54] J. Stangret and E. Kamieńska-Piotrowicz, "Effect of tetraphenylphosphonium and tetraphenylborate ions on the water structure in aqueous solutions; FTIR studies of HDO spectra," Journal of the Chemical Society, vol. 93, no. 19, pp. 3463-3466, 1997.

[55] M. G. Neumann, C. C. Schmitt, and H. M. Maciel, "The effect of monomer aggregation in the photopolymerization of styrenesulfonate," Journal of Physical Chemistry B, vol. 105, no. 15, pp. 2939-2944, 2001.

[56] I. C. Rigoli, C. C. Schmitt, and M. G. Neumann, "The hydrotrope effect on the photopolymerization of styrenesulfonate initiated by Ru complexes," Journal of Photochemistry and Photobiology A, vol. 188, pp. 329-333, 2007.

[57] H. E. Bachofner, F. M. Beringer, and L. Meites, "Diaryliodonium salts. V. The electroreduction of diphenyliodonium salts," Journal of the American Chemical Society, vol. 80, no. 16, pp. 4269-4274, 1958.

[58] S. Fung, S. C. Moratti, S. C. Grahan, and R. H. Friend, "Photoinduced doping in conjugated polymers," Synthetic Metals, vol. 102, p. 1167, 1999.

[59] H. J. Timpe, M. Schmidt, and L. Fisera, "Photochemistry and Photophysics of 3-(2-isoxazolinyl)-phenylketones," Journal für Praktische Chemie, vol. 330, p. 735, 1988. 


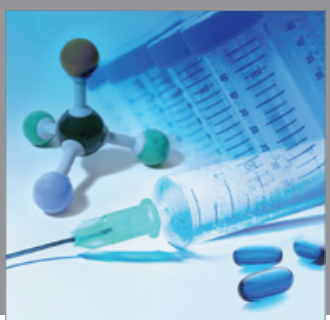

International Journal of

Medicinal Chemistry

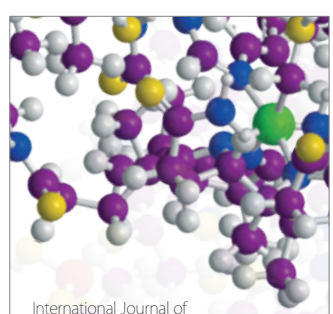

Carbohydrate Chemistry



The Scientific World Journal
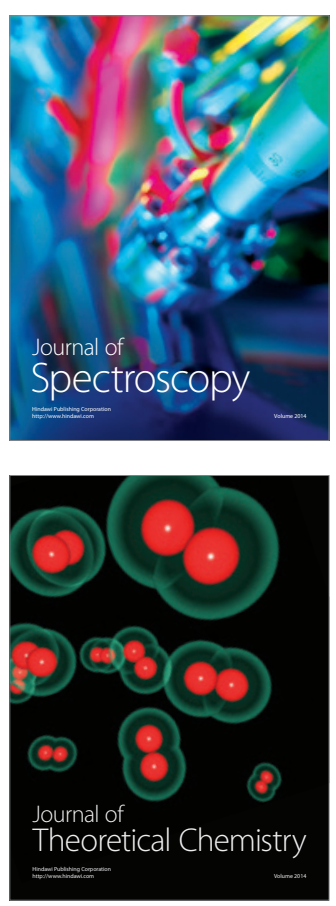
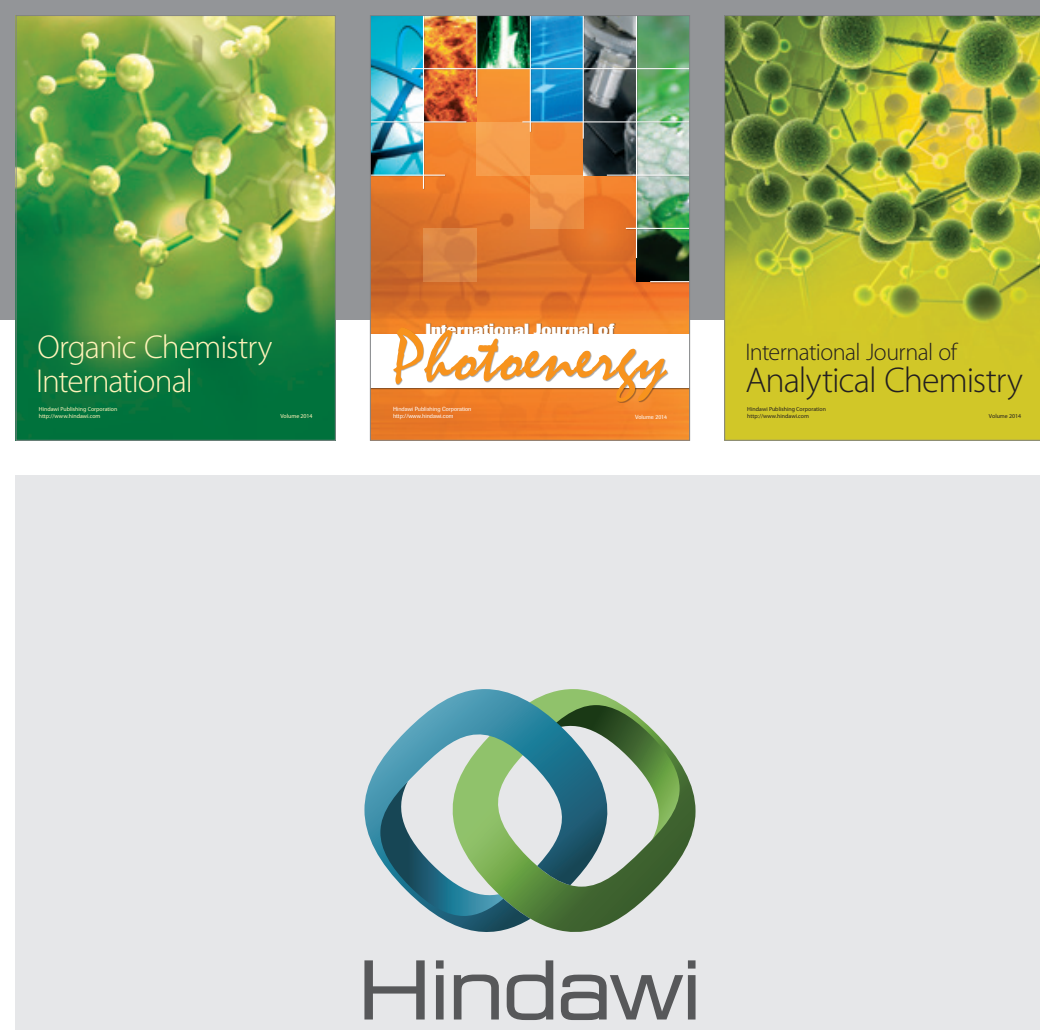

Submit your manuscripts at

http://www.hindawi.com
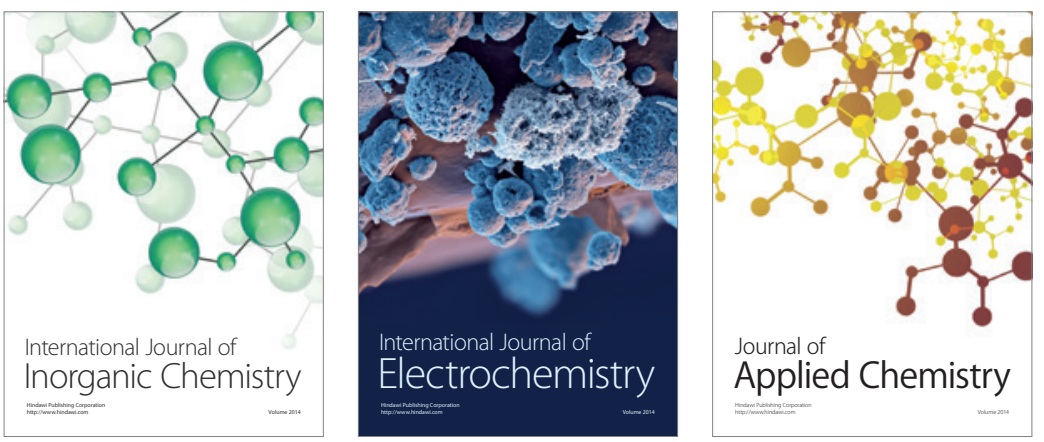

Journal of

Applied Chemistry
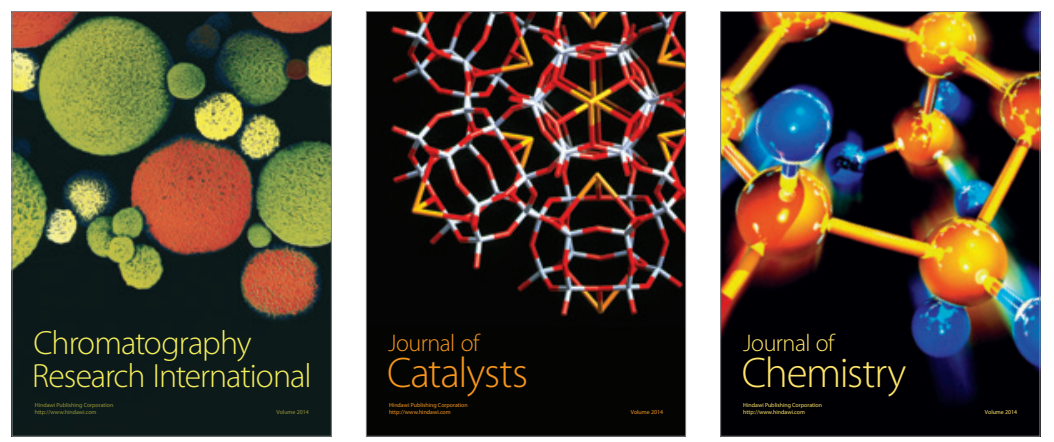
